\title{
未次间冰期以来北大西洋深层海温与青藏高原气温的 千年尺度位相关系及其演变
}

\author{
肖栋 ${ }^{(1)}$, 赵平 ${ }^{(12) *}$, 王跃 ${ }^{(1)}$, 田沁花 ${ }^{(3)}$, 周秀䩀 ${ }^{(12)}$ \\ (1) 中国气象科学研究院, 北京 100081 ; \\ (2) 中国气象科学研究院, 灾害天气国家重点实验室, 北京 100081; \\ (3) 国家气候中心, 北京 100081 \\ * 联系人, E-mail: zhaop@cma.gov.cn
}

2013-05-20 收稿, 2013-07-03 接受, 2013-09-03 网络版发表

国家科技基础性工作专项(2011FY120300)和国家自然科学基金(41001058)资助

\begin{abstract}
摘要 采用代用资料研究了北大西洋深层海温和青藏高原气温自末次间冰期以来在千年 尺度上的位相关系及其变化. 通过对比分析和小波交叉谱分析表明，自末次间冰期以来二 者同位相和反位相关系交替出现，同位相的持续时间相对较短，而反位相的持续时间较 长, 并且二者同位相和反位相关系的转换在间冰期比在冰期频繁, 北大西洋深层海温与青 藏高原气温的位相关系大体被北大西洋气温(格陵兰冰芯氧同位素)与青藏高原气温所验 证. 此外, 北大西洋海表温度可能是北大西洋深层海温在千年尺度上影响青藏高原气温的 一个重要因子。
\end{abstract}

关键词

北大西洋深层海温

北大西洋气温

北大西洋海表温度

青藏高原气温

位相关系

千年尺度

温盐环流
20 世纪 90 年代初期, 关于格陵兰冰芯 $\delta^{18} \mathrm{O}$ 记录 的研究揭示了次米兰科维奇尺度(亚轨道尺度)的冷 暖交替 ${ }^{[1,2]}$, 这些冷、暖期被称作冰阶、间冰阶. 冰阶、 间冰阶之间的交替称为 DO 循环(Dansgaard/Oeschger Oscillation), 亦统称为千年尺度变化 ${ }^{[3]}$. 千年尺度气 候变率是全球广泛存在的, 大体上同步变化, 它是古 气候当中重要的、具有支配地位的时间尺度之一, 也 是古气候研究的主要时间尺度之一 ${ }^{[4]}$. 目前关于千年 尺度气候变率的机制, 通过数值模拟和重建资料研 究, 多数学者认为千年尺度气候变率很可能和温盐 环流的内部变率有关 ${ }^{[4,5]}$.

温盐环流是地球气候系统的一个重要组成部分, 是全球经向质量输送的重要纽带 ${ }^{[6,7]}$, 其变化对全 球 ${ }^{[8]}$ 和中国气候和环境 ${ }^{[9]}$ 都具有明显的影响. 温盐环 流变化的关键地区北大西洋具有多时间尺度变化的 特征, 在各种尺度上都和中国气候有一定联系. 北大
西洋海表温度变化引起的环流异常通过上下游波动 能量的频散可以影响到中国季节和年际气候变 率 $^{[10 \sim 13]}$. 在多年代际尺度上, 北大西洋海表温度变 化呈现多年代际尺度的涛动, 它与温盐环流的内在 变率存在联系, 其暖位相可以增强亚洲夏季风 ${ }^{[14]}$ 和 减弱亚洲冬季风[15]，以及影响中国大部分地区的气 温变化 ${ }^{[15]}$ 和印度季风(16]等. 重建代用资料 ${ }^{[17]}$ 和数值 模拟结果 ${ }^{[18]}$ 表明, 北大西洋经向反转流在百年尺度 上也可影响中国气候. 在千年尺度上, 北大西洋气候 和中国冰芯 ${ }^{[19]}$ 、黄土 ${ }^{[20]}$ 和石笋记录 ${ }^{[17]}$ 都存在一定联 系. 例如, 在过去 $60 \mathrm{ka}$, 格陵兰气温和东亚冬季风 强度大体上是相关联的, 数值模拟表明, 北大西洋经 向反转流通过激发北半球西风异常来把信号传递到 亚洲季风区 ${ }^{[21]}$. 已有研究主要关注于北大西洋和亚 洲季风的关系, 然而, 对北大西洋和青藏高原的关系 研究还不够, 尤其是关于二者千年尺度位相关系及 
其演变的研究更少.

占中国陆地面积 $1 / 4$ 、平均海拔高度 $4 \mathrm{~km}$ 以上的 青藏高原, 以其独特的地理位置保存了分辨率较高 的冰芯资料，这些冰芯资料记录了青藏高原自末次 间冰期以来的环境气候变化, 对亚洲气候具有重要 的指示意义. 由于亚洲气候在千年尺度和温盐环流 存在一定联系, 因此, 在千年尺度上认识北大西洋海 温与青藏高原气候的关系及其演变对于理解亚洲气 候的变化规律及可能机制具有重要意义. 鉴于此, 本 文采用北大西洋底栖有孔虫壳体的氧同位素记录和 古里雅冰芯的氧同位素记录为例探讨北大西洋深层 海温与青藏高原气温末次间冰期以来的位相关系及 其变化, 着重关注千年尺度的位相关系及其变化, 这 里千年尺度指一千至一万年的时间尺度.

\section{1 资料}

古里雅冰芯采样于青藏高原西北部平均海拔 $6700 \mathrm{~m}$ 的古里雅冰川, 采样点位于 $81^{\circ} 30^{\prime} \mathrm{E}, 35^{\circ} 12^{\prime} \mathrm{N}$, 古里雅冰芯的氧同位素记录代表青藏高原的气 温 ${ }^{[22,23]}$. 北大西洋底栖有孔虫类壳体的氧同位素记 录采样于北大西洋 $2179 \mathrm{~m}$ 的深海, 采样点位于 $14^{\circ} 2^{\prime} \mathrm{W}, 55^{\circ} 9^{\prime} \mathrm{N}$, 其代表北大西洋深层水温度 ${ }^{[24]}$. 古 里雅氧同位素记录和北大西洋有孔虫类壳体的氧同 位素记录都可追溯到距今 $130 \mathrm{ka}$ 的末次间冰期, 它 们的平均时间分辨率分别为 $113 \mathrm{a}$ 和 $427 \mathrm{a}$. 由于北大 西洋有孔虫类壳体的氧同位素记录的时间分辨率在 末次间冰期较小, 需要采用较高分辨率的代用资料 进行验证. 格陵兰冰芯资料对北大西洋的大尺度气 温和海温都有一定的代表性, 因此, 我们采用格陵兰 冰芯氧同位素资料来对二者末次冰期的位相关系做 验证, 来增强二者关系的可信度. 格陵兰冰芯氧同位 素记录代表北大西洋气温，资料的平均时间分辨率 为 $25 \mathrm{a}$, 采样点位于 $37^{\circ} 38^{\prime} \mathrm{W}, 72^{\circ} 35^{\prime} \mathrm{N}^{[25]}$. 北大西洋 深层海温影响青藏高原气温很有可能是通过改变海 表温度来实现的，目前海底沉积物都是沿着大陆架 采样的, 因此, 重建的海表温度对沿岸流的代表性较 好, 对整个大西洋海表温度的代表性可能并不很好. 尽管如此, 它对于理解北大西洋深层海温和青藏高 原气温的关系仍具有重要的指示意义. 因此, 我们利 用 Bard 等人 ${ }^{[26]}$ 采用海底有机质重建的北大西洋的海 表温度来分析其与青藏高原气温的关系, 采样点位 于 $10^{\circ} 0^{\prime} \mathrm{W}, 37^{\circ} 5^{\prime} \mathrm{N}$, 平均时间分辨率为 $455 \mathrm{a}$. 本文拟
分析末次间冰期以来北大西洋深层海温与青藏高原 气温的位相关系及其演变, 并用北大西洋气温和海 温资料, 通过直观比较和小波交叉谱定量分析来验 证上述关系.

\section{2 北大西洋深层海温与青藏高原气温的千 年尺度位相关系及其演变}

图 1 给出了末次间冰期以来的古里雅冰芯和北 大西洋底栖有孔虫壳体的氧同位素记录, 它们分别 代表青藏高原气温和北大西洋深层海温. 总体而言, 二者大体经历了末次间冰期和末次冰期, 并都具有 $43 \mathrm{ka}$ 的斜率周期和 $21 \mathrm{ka}$ 的岁差周期且同位相变化 (图略). 采用交叉谱分析发现二者的相关在 6.6, 5.5, 2.3，1.8，0.9 ka 尺度上通过了 $90 \%$ 的置信度检验(图 略), 然而进一步比较可以发现二者在千年尺度上的 位相关系在不同时段是不一样的．根据二者千年尺 度上位相关系的变化, 将过去 $131 \mathrm{ka}$ 划分为 11 个时 段，下文将按时段分别叙述二者的位相关系及其演 变. 在第 1 时段(131 124 ka BP), 青藏高原气温经历 了 3 个波峰, 北大西洋深层海温则急剧升高, 虽然二 者变化趋势不同，但二者在千年尺度上的变化大体 是相反的; 在第 2 时段(124 121 ka BP)二者总体略有 下降趋势, 均经历了 3 个千年尺度同位相变化的波谷; 二者在第 3 时段(121 110 ka BP)均呈现明显下降趋 势, 叠加于下降趋势之上的千年尺度变化呈现反位 相关系，尤其在该阶段的中后期比较明显; 与第 2 时 段类似, 青藏高原气温和北大西洋深层海温在第 4 时 段(110 107 ka BP)均经历了 2 个千年尺度同位相的 波谷; 然而，二者在第 5 时段(107 92 ka BP)则转换 为反位相关系，该时段青藏高原气温的岁差周期峰 值比较明显; 与第 2 和 4 时段类似，二者在第 6 时段 (92 88 ka BP)经历了 2 个同位相波谷; 在第 7 时段 (88 74 ka BP), 青藏高原气温和北大西洋深层海温 再次转变为反位相关系, 该时段青藏高原气温的岁 差周期峰值也比较明显; 北大西洋深层海温在第 8 时 段(74 57 ka BP)经历了 5 个波谷，且与青藏高原气温 同位相变化; 北大西洋深层海温在第 9 时段(57 $12 \mathrm{ka} \mathrm{BP})$ 呈现下降趋势，青藏高原气温呈现出 2 个明 显的岁差循环，但在千年尺度上，二者存在比较明显 的反位相关系; 在第 10 时段 $(12 \sim 7 \mathrm{ka} \mathrm{BP})$ 二者经历了 2 个波谷, 大体上呈现同步变化; 在第 11 时段(7 0 ka BP)，青藏高原气温先降低后升高，而北大西洋深层 


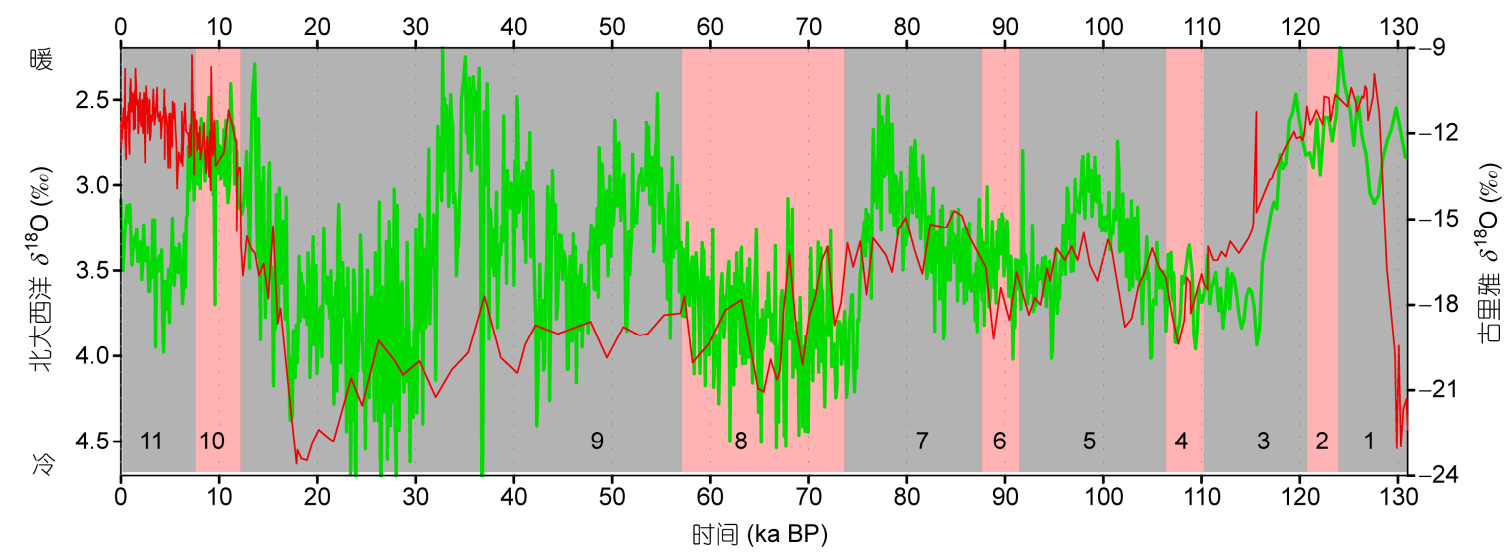

图 1 末次间冰期以来北大西洋底栖有孔虫类氧同位素记录(红线)和青藏高原古里雅冰芯氧同位素记录(绿线) 按照二者位相关系的变化, 将过去 $131 \mathrm{ka}$ 划分为 11 个时段, 分别用阴影和数字标记

海温先升高后降低, 二者大体为反位相关系. 可见, 北大西洋深层海温与青藏高原气温在千年尺度上存 在一定联系, 既存在同位相变化, 又存在反位相变化, 二者交替出现，其位相关系在间冰期的转换比在冰 期频繁.

在末次冰期(74 12 ka BP)北大西洋深层海温的 资料分辨率相对较低, 因此, 采用分辨率较高的格陵 兰冰芯氧同位素资料作为补充，格陵兰冰芯氧同位 素资料代表北大西洋气温, 和北大西洋海温存在一 定联系 ${ }^{[25]}$. 这里比较其和青藏高原气温在末次冰期 期间千年尺度上的关系, 以增加北大西洋深层海温 与青藏高原气温之间位相关系的可信度. 从图 2 可以 看出, 在 74 68 ka BP 时段, 北大西洋气温和青藏高 原气温大体是同位相关系, 但北大西洋气温的位相 略超前约 $1 \mathrm{ka}$, 在 68 56 ka BP 时段, 二者呈现在百
年尺度上为反位相, 在接近万年尺度大体为同位相 关系，与图 1 中该时段的位相关系是基本一致的. 在 58 31 ka BP 时段(除 52 49 ka BP 外)二者主要呈现为 反位相关系, 这和图 1 中该时段的位相关系是一致的. 在 29 12 ka BP, 二者分别呈现为同位相关系, 和图 1 中的位相关系并不一致. 总体而言, 在末次冰期格陵 兰冰芯氧同位素和古里雅冰芯氧同位素在 68 31 ka $\mathrm{BP}$ 时段的位相关系和图 1 中的位相关系是基本一致 的，大体验证了末次冰期北大西洋深层海温与青藏 高原气温的位相关系.

为了定量揭示北大西洋深层海温与青藏高原气 温的位相关系，我们把时间分辨率较高的格陵兰冰 芯和古里雅冰芯氧同位素记录插值到时间分辨率为 $100 \mathrm{a}$ 的时间格点上，对其进行 $21 \mathrm{ka}$ 的高通滤波后， 保留轨道尺度以下的变化进行了小波交叉谱分析,

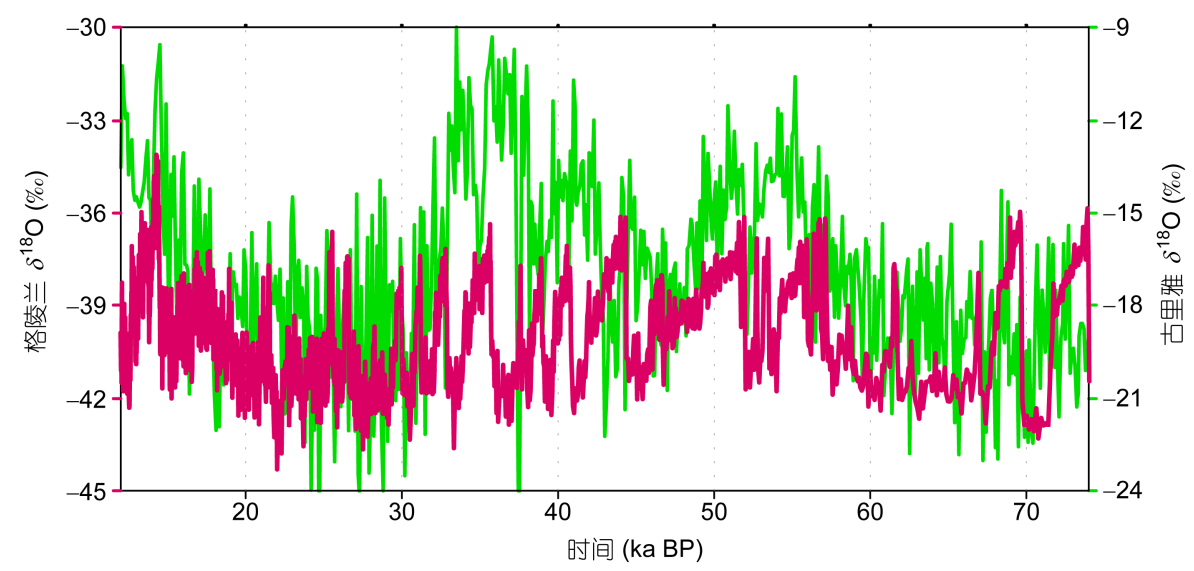

图 2 末次冰期(74 12 ka BP)格陵兰冰芯氧同位素序列(玫瑰红线)和古里雅冰芯氧同位素序列(绿线) 
本文采用的是 Morlet 小波 ${ }^{[27,28]}$. 从图 3 可以看出, 在 131 85 ka BP 时段有 0.8 8 ka 周期, 在 74 0 ka BP 时 段有 $0.8 \sim 6.4 \mathrm{ka}$ 周期. 具体来讲, 在 131 110 ka BP 时段有 $6 \sim 8 \mathrm{ka}$ 同位相的周期, 验证了图 1 中第 1 和第 3 时段的位相关系; 在约 $120 \mathrm{ka} \mathrm{BP}$ 有约 $2.5 \mathrm{ka}$ 的同 位相周期, 大体和第 2 阶段的位相关系是一致的; 二 者在 $100 \mathrm{ka} \mathrm{BP}$ 前后 $0.8 \sim 2 \mathrm{ka}$ 周期分别为同位相和反 位相, 大体和图 1 中第 4 和第 5 时段的位相关系是对 应的; 在 $90 \mathrm{ka}$ BP 附近 0.7 1.2 ka 的周期呈现同位相, 这和第 6 时段的位相关系是一致的; 在 $80 \mathrm{ka} \mathrm{BP}$ 时段 约 $1.5 \mathrm{ka}$ 的周期是反位相关系, 与第 7 时段的位相关 系是一致的; 在 85 58 ka BP 时段有明显的 10 12.8 ka 的同位相变化, 与第 8 时段的同位相关系是对应的, 和第 7 时段的位相关系不同, 而在 74 50 ka BP 时段 $0.8 \sim 5 \mathrm{ka}$ 的周期呈现一定程度的同位相, 与第 8 时段 的同位相关系是一致的; 在 50 30 ka BP 时段 2 5 ka 的周期呈现反位相变化, 和第 9 时段的位相大部分是 一致的; 在 30 11 ka BP 时段 0.8 2 ka 的周期大体上 呈现同位相关系, 和第 9 时段后半段的反位相关系不 一致; 在 11 0 ka BP 时段 5 6.4 ka 周期呈现同位相变 化, 1.5 3 ka 周期呈现反位相变化, 部分和第 10 和 11 时段的位相关系是一致的. 总体而言, 北大西洋气温
和青藏高原气温的位相关系及其演变大体上可以验 证北大西洋深层海温与青藏高原气温的位相关系及 演变.

北大西洋深层海温影响青藏高原气温很可能是 通过改变北大西洋海表温度来实现的, 那么, 北大西 洋海表温度在千年尺度上是否和青藏高原气温存在 联系呢? 于是, 图 4 给出了北大西洋海表温度和青藏 高原气温代用序列. 在末次间冰期时段(约 $76 \mathrm{ka} \mathrm{BP}$ 以前), 北大西洋海表温度和青藏高原气温除了在 106 104，88 86，81 79 ka BP 3 个时段为同位相外, 其余时段均大致为反位相关系. 在末次冰期和全新 世时段(约 $76 \mathrm{ka} \mathrm{BP}$ 以后), 76 57 ka BP二者大体呈现 同位相，在其余时段大体呈现为反位相关系. 从整个 时段和图 1 对比可以发现, 在绝大多数时段, 图 4 中 二者的位相关系和图 1 中的大体是一致的. 我们采用 交叉谱分析了北大西洋海表温度和青藏高原气温在 各种时间尺度上的关系(图略)，结果表明，二者在 3, $1.8,1.47,0.9 \mathrm{ka}$ 时间尺度上都具有显著的相关关系 (通过 $95 \%$ 的置信度检验). 进一步说明, 北大西洋海 表温度和青藏高原气温在千年尺度上具有一定联系， 而且北大西洋海表温度可能是北大西洋深层海温在千 年尺度上影响青藏高原气温的一个重要因子.

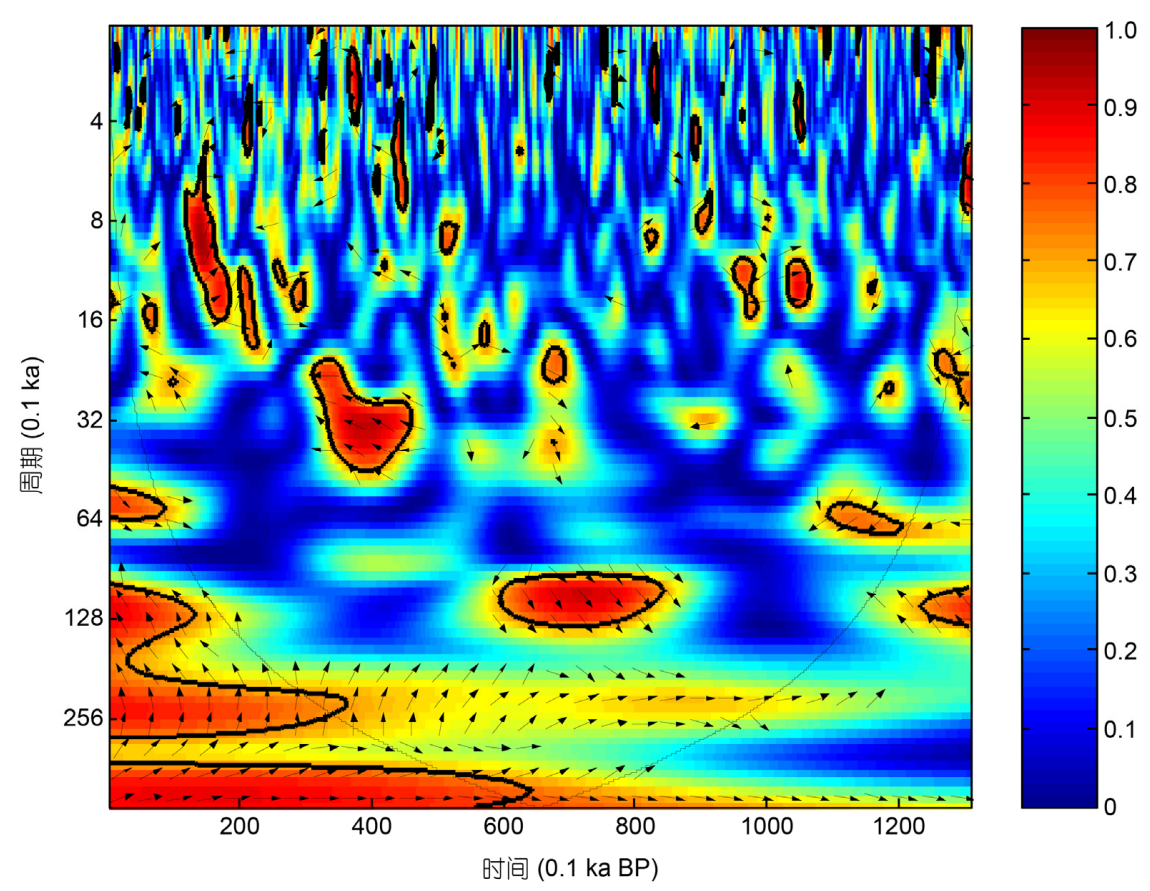

图 $321 \mathrm{ka} \mathrm{BP}$ 高通滤波后古里雅冰芯和格陵兰冰芯氧同位素记录的小波交叉谱 彩色阴影为交叉谱值. 抛物线内区域为不受序列边界影响的区域, 箭头向右表示同位相, 箭头向左表示反位相 


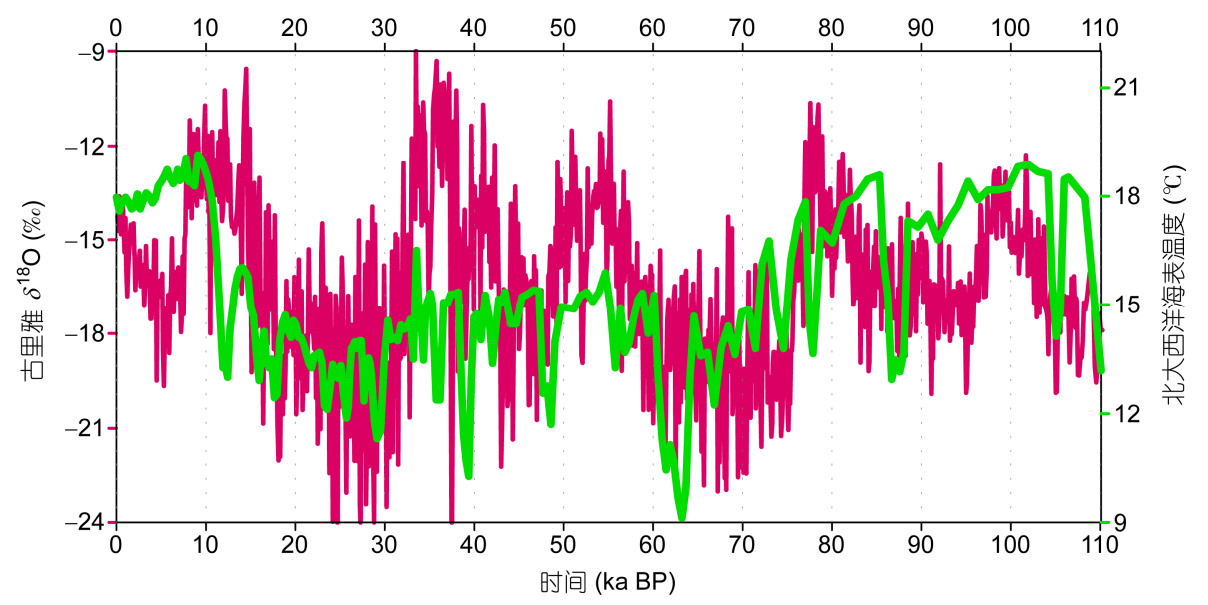

图 $4110 \mathrm{ka} \mathrm{BP}$ 古里雅冰芯氧同位素(玫瑰红线)和北大西洋海表温度(绿线)序列

\section{3 总结和讨论}

综上所述, 北大西洋深层海温和青藏高原气温 在千年尺度变化上存在一定联系, 既有同位相变化, 又有反位相变化, 二者的同位相与反位相关系交替 出现, 间冰期内的转换更加频繁, 而且冰期和间冰期 的同位相关系持续时间都比反位相关系的持续时间 短. 北大西洋深层海温与青藏高原气温的位相关系 及其演变大体被北大西洋气温(格陵兰冰芯氧同位素) 和青藏高原气温所验证. 此外, 在千年尺度上北大西 洋深层海温可能是通过改变当地海表温度来影响青 藏高原气温的.

目前研究认为千年尺度气候变化的机制主要和 温盐环流的 3 种模态有关, 即现代模、冰期模和海因 希里模 ${ }^{[4]}$. 它们分别称为双原模、单洜模和无原模, 分别对应于北大西洋不同的经向海表温度结构, 即 一致偏冷、南冷北暖和一致偏暖 ${ }^{[3]}$. 不同的北大西洋 经向海温结构对青藏高原气温的影响可能是不一样 的, 因此, 这些模态的变异或者转换可能是北大西洋 深层海温与青藏高原气温位相关系演变的成因. 数
值模拟是验证代用资料之间关系的物理机制的有力 工具 ${ }^{[29 ~ 32]}$. 随着气候模式的持续发展和计算机运算 能力的提高, 北大西洋深层海温与青藏高原气温二 者联系的内在机制还有待于采用气候模式进行深人 研究.

通过代用资料的对比, 本文揭示了北大西洋深 层海温和青藏高原气温在千年尺度上的位相关系及 其演变, 并用北大西洋气温进行了验证, 得到了一些 结果. 然而由于资料分辨率所限, 本文的分析结果主 要来自于对比分析, 大体被小波交叉谱的定量分析 所验证. 然而非均匀分辨率的代用资料中绝大多数 数值不在整百年上, 峰值和谷值会因插值而被抹平. 再者, 滤波分析会使得一些剧烈变化时段的数值变 得不准确. 因此, 部分较小尺度(百年至千年尺度)和 剧烈变化时段(末次冰盛期至全新世)的位相关系可 能并不太准确. 目前关于北大西洋深层海温和青藏 高原气温在千年尺度上位相关系的研究受到资料分 辨率所限, 有待于更高分辨率的资料来进一步丰富 和证实.

\section{参考文献}

1 Dansgaard W, Johnsen S J, Clausen H B. Evidence for general instabil ity of past climate from a 250-ka ice core record. Nature, 1993, 364: 218-220

2 Grootes P M, Stuiver M, White J W C. Comparison of oxygen isotope records from the GLSP2 and GRIP Greenland ice cores. Nature, 1993, 366: 552-554

3 王绍武, 谢志辉. 千年尺度气候变率的研究. 地学前缘, 2002, 9: 143-153

4 Alley R B, Clark P U, Keigwin L D, et al. Making sense of millennial-scale climate change. In: Clark P U, Webb R S, Keigwin L D, eds. Mechanisms of Global Climate Change at Millennial Time Scales. Washington, DC: American Geophysical Union, 1999. 385-394 
5 Friedrich T, Timmermann A, Menviel L, et al. The mechanism behind internally generated centennial-to-millennial scale climate variability in an earth system model of intermediate complexity. Geosci Model Dev, 2010, 3: 377-389

6 Broecker W S. The great ocean conveyor. Oceanogr, 1991, 4: 79-89

7 Trenberth K E, Caron J M. Estimates of meridional atmosphere and ocean heat transports. J Clim, 2001, 14: 3433-3443

8 Vellinga M, Wood R A. Global climatic impacts of a collapse of the Atlantic thermohaline circulation. Clim Change, 2002, 54: 251-267

9 李双林, 王彦明, 郜永祺. 北大西洋年代际振荡(AMO)气候影响的研究评述. 大气科学学报, 2009, 32: 458-465

10 Palmaer T N, Sun Z B. A modelling and observational study of the relationship between sea surface temperature in the North-West Atlantic and the atmospheric general circulation. Q J R Meteorol Soc, 1985, 111: 947-975

11 刘晓东, 侯萍. 青藏高原中东部夏季降水变化及其与北大西洋涛动的联系. 气象学报, 1999, 57: 561-570

12 徐海明, 何金海, 董敏. 江淮人梅的年际变化及其与北大西洋涛动和海温异常的联系. 气象学报, 2001, 59: 694-706

13 刘焕才, 段克勤. 北大西洋涛动对青藏高原夏季降水的影响. 冰川冻土, 2012, 34: 311-318

14 Wang Y, Li S, Luo D. Seasonal response of Asian monsoonal climate to the Atlantic Multidecadal Oscillation. J Geophys Res, 2009, 114: D02112, doi: 02110.01029/02008JD010929

15 Li S L, Bates G T. Influence of the Atlantic Multidecadal Oscillation (AMO) on the winter climate of East China. Adv Atmos Sci, 2007, 24: $126-135$

16 Feng S, Hu Q. How the North Atlantic Multidecadal Oscillation may have influenced the Indian summer monsoon during the past two millennia. Geophys Res Lett, 2008, 35: L01707, doi: 01710.01029/02007GL032484

17 Wang Y J, Cheng H, Edwards R L, et al. A high-resolution absolute-dated late Pleistocene Monsoon record from Hulu Cave, China. Science, 2001, 294: 2345-2348

18 程军, Liu Z Y, He F, 等. 温盐环流在百年尺度上影响中国气候的一个数值模拟证据. 科学通报, 2010, 55: 2406-2412

19 Thompson L G, Yao T, Davis M E, et al. Tropical climate instability: The last glacial cycles from a Qinghai Tibetan ice core. Science, 1997, 276: 1821-1825

20 Ding Z L, Rutter N W, Liu T S, et al. Correlation of Dansggard-Oeschger cycles between Greenland ice and Chinese loess. Paleoclimates, 1998, 4: 281-291

21 Sun Y B, Clemens S C, Morrill C, et al. Influence of Atlantic meridional overturning circulation on the East Asian winter monsoon. Nat Geosci, 2011, 5: 46-49

22 Yao T D, Lonnie G, Thompson E M, et al. Climatological significance of $\delta^{18} \mathrm{O}$ in the north Tibetan ice cores. J Geophys Res, 1996, 101: 29531-29537

23 Xiao D, Zhao P, Wang Y, et al. Modeling the climatic implications and indicative senses of the Guliya $\delta^{18} \mathrm{O}$-temperature proxy record to the ocean-atmosphere system during the past $130 \mathrm{ka}$. Clim Past, 2013, 9: 735-747

24 Oppo D W, McManus J F, Cullen J L. Evolution and demise of the Last Interglacial warmth in the North Atlantic. Quat Sci Rev, 2006, 25: 3268-3277

GRIP Members. Climate instability during the last interglacial period recorded in the GRIP ice core. Nature, 1993, 364: 203-207 $1321-1324$

27 Torrence C, Compo G P. A practical guide to wavelet analysis. Bull Amer Meteorol Soc, 1998, 79: 61-78

28 Grinsted A, Moore J C, Jevrejeva S. Application of the cross wavelet transform and wavelet coherence to geophysical time series. Nonlinear Process Geophys, 2004, 11: 561-566

29 Cane M A, Braconnot P, Clement A, et al. Progress in paleoclimate modeling. J Clim, 2006, 19: 5031-5057

30 Jiang D, Zhang Z S. Paleoclimate modelling at the Institute of Atmospheric Physics, Chinese Academy of Sciences. Adv Atmos Sci, 2006, 23: $1040-1049$

31 肖栋, 周秀骥, 赵平. 过去千年中国东部气候变化的数值模拟研究. 中国科学：地球科学, 2012, 42: 1414-1428

32 王跃, 翦知涽, 赵平, 等. 全新世太阳活动驱动的太平洋上层热力结构的瞬变演化. 科学通报, 2013, 58: 379-384 